\title{
Migration Policy Framing in Political Discourse: Evidence from Canada and the USA
}

\author{
Sanja Hajdinjak, Marcella H. Morris, and Tyler Amos
}

\begin{abstract}
How do parties discuss migration policy in legislative speeches? Legislative bodies are an arena for verbal conflicts where the parties vie for their ideological interests but also sharpen new rhetorical figures. Political parties develop policy stances strategically different from those of competing parties and elucidate those stances through legislative debates and public statements. A large body of literature argues that some issues, like migration, fall in a gap between established societal cleavages over which parties do not have robust, issue-specific ownership. More recent research suggests migration may be a part of a new transnational cleavage that pits cosmopolitan sensibilities against nationalist sentiments in a conflict over issue ownership and policy framing. Building off this debate, we hypothesize that parties discuss migration topics by diverting attention to subcomponents of migration policy over which they have established issue ownership. Using machine learning techniques, we test this assertion by measuring the differences in salience and framing of migration-related topics over time in the debates of the lower houses of Canada and the United States - the Canadian House of Commons and the United States' House of Representatives from 1994 to 2016. We find that there are substantive differences in the emphasis on and framing of the migration policy between the two ideological blocks. Democrats in the USA and liberals in Canada emphasize subcomponents of the migration debate which they traditionally own, such as welfare and humanitarian aspects. Both conservative blocks do the same by framing their discussion of migration through a focus on security and legalistic aspect of migration. However, due to strong polarization in the USA, the differences in the emphasis on the issues traditionally owned by the two ideological camps are stronger in the USA than in Canada.
\end{abstract}

\author{
S. Hajdinjak ( $ه)$ \\ University of Vienna, Vienna, Austria \\ M. H. Morris \\ Emory University, Atlanta, GA, USA \\ T. Amos \\ University of Chicago, Chicago, IL, USA
}

(C) The Author(s) 2020

E. Deutschmann et al. (eds.), Computational Conflict Research,

Computational Social Sciences, https://doi.org/10.1007/978-3-030-29333-8_5 
Keywords Migration policy · Issue ownership · Policy framing · Polarization · United States · Canada

\section{Introduction}

Conflict is part and parcel of politics on the international, national, and local levels. Morgenthau's influential work defined politics as a struggle for power (Morgenthau 1960). Originating in legislative bodies of modern democracies, parliamentary debates offer an optimal source of information for an in-depth analysis of political conflict (Grimmer and Stewart 2013). Migration policy, the substantive focus of this chapter, is not only a prominent, much debated political and research issue, but its framing in legislative bodies also poses a theoretical puzzle.

Most political issues, as discussed in the issue ownership literature, fall in either the liberal or conservative political domain. This proposal is based on the nature of liberal and conservative ${ }^{1}$ political issue ownership where parties develop stances on issues that resonate with voters so a common citizen would be able to place a particular issue or issue frame with the "correct" political party (Petrocik 1996). For instance, voters might reasonably associate social welfare policy domains with liberal parties or military and defense policies with conservative parties. In this case, on these two issues, the two political camps have issue ownership. However, migration policy has been argued to represent an exception as it creates conflicts within both ideological camps-market liberalism versus value conservatism (for the conservatives) and international solidarity versus welfare state/labor market protectionism (for the liberals) (Odmalm 2011a). This leads us to the question: how do liberal and conservative parties discuss migration issues in parliamentary speeches?

The literature suggests parties compete against each other by framing policies so they resonate with voters and their own platforms (Chong and Druckman 2007a, b; Nelson and Kinder 1996). We suggest that parties debate migration policy by emphasizing the subcomponents of the migration policy which they own. In addition, we suggest parties will emphasize their strengths more in polarized party systems as this allows their rhetoric to capture the median voter more regularly. We expect in a less polarized system, there will be less difference in emphasis parties place on issues they own.

While much of the literature on issue ownership and policy framing-upon which our work builds - focuses on campaigning and media statements, this chapter analyzes migration policy in legislative speeches. Lefevere et al. (2017) argue policy framing is aimed at either winning the rhetorical struggle or at gaining

\footnotetext{
${ }^{1}$ We refer to liberal and conservative ideology in the North American context, which follows the lines of the left-right political spectrum. Liberal ideology is identified as left-leaning, egalitarian, multicultural, and in support of social policies that appeal to the working class. Conservative ideology stands for right-leaning, orientation to tradition, and protection of private property and individualism.
} 
public support. Thus, we argue floor speeches allow for members and their staff to sandbox ideas for talking points or policy frames in a low stakes environment prior to developing or revising a party manifesto, campaign platform, or press release. Moreover, being the center stage of the formal conflict between the parties, legislative speeches are a weapon parties use to demonstrate their strengths in the rhetorical arena.

To test our hypotheses regarding migration policy framing and polarization, we use a most similar comparative case study framework (Anckar 2008; Gerring 2009) and select the cases of the United States and Canada. Both economies were founded largely by immigrants and the discussion on migration policy is a constant question for decades in both the USA and Canada. While the two share a clear ideological divide between liberal and conservative camps, they differ regarding the degree of political polarization - the effect of which we are interested in exploring through our comparative case study design.

Our analysis includes debates in the lower houses of the national legislature in Canada and the United States - the Canadian House of Commons and the United States' House of Representatives from 1994 to 2016. As the migration debate is one that has existed in the political sphere of Canada and the United States since their founding as nations of immigrants, we test our hypotheses on a wide, contemporary timeframe that captures both liberal and conservative legislatures and executives as well as different waves of migration patterns from a variety of conflicts spanning much of the world.

Methodologically, we rely on unsupervised machine learning for our analysis of text data. The availability of the legislative speeches in easily accessible digital form and the computational power necessary for the analysis of large datasets at hand have jointly led to a surge of interest in analysis using automated text analysis techniques (see also Maerz and Puschmann in the chapter "Text as Data for Conflict Research: A Literature Survey" of this volume). Automated text analysis can be used to discover new patterns and structures in the political texts, as well as to verify how known covariates affect these patterns. We use structural topic modeling to identify specific migration-related topics in the dataset and to understand the differences in issue salience and policy framing between the parties.

The chapter is structured as follows. Section 1 outlines the relevant theoretical literature and introduces hypotheses. Section 2 summarizes research design, data, and methods. Section 3 presents our results and discusses the implications. Section 4 summarizes findings and real-world implications of this work and discusses future avenues we see as viable and helpful in this research realm.

\section{Theory}

\subsection{Party-Based Issue Ownership}

Issue ownership is an established theoretical framework within which most work focuses on party manifestos and campaigns. Issue ownership represents "the 
perceived competence in handling issues and problems" (Stubager and Slothuus 2013). Generally, the issue ownership framework includes the following: campaigns setting the criteria for voter choice, candidates emphasizing issues that present themselves as advantaged and their opponent as disadvantaged during a campaign to influence voter choice in the election. In the context of our study, issue ownership campaigning has been shown to take place in presidential elections in the United States and in national elections in Canada (Bélanger 2003; Petrocik 1996). Walgrave and De Swert (2007) find that both the party, from the time of inception and their driving manifesto, and the media, from the discussion surrounding the party and their actions, contribute to the establishment of issue ownership although the direction of the causal arrow remains unclear between the two. Issue ownership comprises more than just partisanship or attitudes; rather it includes constituencybased ownership and perceived development as it relates to the real world (Stubager and Slothuus 2013).

While issue ownership is a well-defined concept that clearly matters for voters choosing between parties and candidates in the ballot box, it is established through party platforms, manifestos, and, via media coverage, in everyday politicking (Lefevere et al. 2015). Scholars suggest that issue ownership can also be identified in legislative speeches (Green-Pedersen and Mortensen 2010; Sulkin 2005; Vliegenthart and Walgrave 2011). We use transcripts from the floors of national legislatures to see how issue ownership relates to the migration policy in political debates. In the next section, we discuss policy framing as a method that political actors use in political debates and communication.

\subsection{Policy Framing}

According to Sniderman and Theriault (2004), a framing effect is a "central organizing idea or story line" that relates the policy domain in contention to the public such that it resonates. Critically, multiple frames can be applied to the same issue and can be placed in competition with each other. Further, frames can be linked through issue ownership to distinct parties (ibid). Within this realm of competition over policy domains and attention from the public, politicians deploy policy frames to compete over the dominant train of thought or association over relevant policy domains (Nelson and Kinder 1996). The issue ownership literature suggests that parties strategically emphasize issues they own to boost electoral prospects. However, when external events or crises force them to address issues their opponents hold an advantage over, parties frame the issues by choosing to focus on a subcomponent of an issue (De Vreese 2005). To provide an example within the context of migration policy, liberals can leverage framing by discussing humanitarian subcomponent of proposed migration policy.

Inherent in the context over policy framing and issue dominance, policymakers compete over multiple audiences. Parties can seek to frame issues for individuals or 
journalists differently and the dominant framing strategies depend on the design and implementation within the particular audience environment (Chong and Druckman 2007b).

Research suggests that there are two factors-quality of frames and competition over policy frames- that play into policy framing's impact on public perceptions that reduce to a question of quality versus quantity of framing (Chong and Druckman 2007a, b). Using experimental design, Chong and Druckman (2007a) find that the strength or quality of the frame matters most to citizens. Moreover, the general debate rallies where competition over policy frames arises. Further, for a policy frame that does not resonate with the population, the resulting preferences rely on the underlying value distribution of the population. However, with a strong frame, public opinion was successfully changed for both competitive and noncompetitive issues (ibid). Thus, inherent in the contest over policy framing is a contest over the lens through which voters view the policy at hand and a successful frame can be hugely beneficial to a party's ability to win the policy debate and achieve policy goals in line with their platform.

Additionally, policy framing can be followed by policy reframing, where parties deliberately shift the policy frame from one issue to another, separate issue. Reframing typically occurs when the debate is topically relevant and matters to the party. Parties push the newly reframed issue to bring the debate back in line with the domain the party owns (Lefevere et al. 2017). The literature argues that parties not only frame and reframe based on issue ownership, but also that issue ownership can be bolstered by proper policy framing, especially in areas of contested ownership like the immigration debate sphere (Hänggli and Kriesi 2010). Empirically, the literature has only started to disentangle the occurrence and effect of framing and reframing in political debates (ibid). Continuing with our previous example of migration policy, liberals could decide not to focus on migration-related humanitarian subcomponent, but rather to impose the debate on humanitarianism proper as a completely distinct policy domain. Next, we consider the role of issue ownership within the migration policy domain specifically as it presents complex dynamics within the debates.

\subsection{Inter-Party Contest over Migration Policy}

Most issue ownership debates scaffold up from Downsian ideas of democracy, in which, parties work to win votes by adopting uniquely dominant policy stances that cross a number of issues (Downs 1957). The tactic of building issue-based ownership is further complicated when one issue, like migration, encompasses multiple, opposed issues. Odmalm (2011b) argues that the questions included in the immigration policy split both traditionally liberal and traditionally conservative parties down the middle, since immigration touches on both moral liberalism and value conservatism while also including international solidarity and welfare system protectionism, thus causing internal strife within both major ideological camps. 
Specifically, he argues migration and other policy areas that have "old" or economic value-laden issues and "new" or socio-cultural issues present these types of internal conflicts for parties (ibid). Odmalm (2012) argues that in cases like these, parties divert to subtopics within the broader topic on which they have a strategic advantage and can hold dominant stances but ultimately are not well equipped to handle a complex idea like migration with its cross-issue composition. This argument is exemplified in research pointing to party restructuring within Europe. On topics of European and national identity, Lahav (1997) finds that traditional right-left party construction "has been reinvented which is mirrored in the debates on immigration within the EU." Further, Helbling (2014) finds policy framing on migration topic occurs across Western Europe based on the political events surrounding the debate and the actors engaged in the debate, thus linking the political debate around migration topics to both issue ownership and policy framing literatures.

This logic of migration and other policy domains that fall between partybased issue ownership potentially restructuring party-issue orientation flows from cleavage theory. Within cleavage theory, first, party systems are "determined in episodic breaks from the past," second, parties are generally inflexible in their approaches to their core issues and beliefs, and third, new parties result in changes to the current systems (Hooghe and Marks 2018). A signal of this could be parties shifting away from issues that reinforce their cores and instead stretch them across multiple, competing issues thus weakening them, and possibly allowing space for new parties to form. An indication of this could be the inability to formulate a cohesive party message on the floors of the legislature on key policy issues like migration (Hooghe and Marks 2018; Odmalm 2011b, 2012). Yet the study of issue ownership and policy framing on migration topics is dominated by studies of European contexts (Helbling 2014; Lahav 1997; Odmalm 2011a). This study works to bring this important question to the shores of North America where a different, but no less salient conversation is ongoing.

\subsection{Hypotheses}

Building on the theoretical frameworks of issue ownership and policy framing and on the literature that uses computational tools to examine the content of political texts, we focus on identifying issue ownership, changes in issue salience, and patterns of policy framing in USA and Canadian lower legislative chamber speeches. According to Odmalm's theory, parties will avoid topics which raise inconsistencies along "old" (economic issues, e.g., taxation and welfare) and "new" (multicultural, environmental) cleavages (Odmalm 2011b). Even when parties change their rhetoric due to popular dissatisfaction with immigration policies, their framing or tone of the issue will reflect the (in)stability of the societal fault lines, and the relative fit between these cleavages and parties' choice of issue framing (economic or sociocultural) (Odmalm and Super 2014). 
We suggest parties will discuss migration in a way that allows them to focus on subcomponents of the migration topic over which they have issue ownership. More precisely, we expect that migration-related issues over which liberal issue ownership is well established, such as poverty, education, weapon control, environment, and health will be more often debated by Democrats in the USA and liberals in Canada. By contrast, we expect Republicans in the USA and conservatives in Canada to discuss more often migration-related topics such as external threats and security. Due to differences in polarization between the two countries, we hypothesize that differences in emphasis on the migration-related topics will be stronger in the USA than in Canada. More specifically, we expect that differences in the emphasis parties place on migration-related subtopics and in policy framing will be smaller between liberals and conservatives in Canada than between Republicans and Democrats in the USA.

\section{Data and Methods}

\subsection{Comparative Case Study Approach}

In order to test our hypotheses, we adopt Mill's most similar systems design (Gerring 2009). The two selected cases are the United States and Canada. The two countries hold the lion's share of power on the North American continent and are geographically isolated from other states. Apart from their common border, the USA has a significant southern land border with Mexico, while Canada has a large but mostly uninhabited northern border. Both face challenges with legal, illegal, and humanitarian-based migration, although to differing degrees in those categories. Both have dominant conservative and liberal ideological camps that historically and competitively vie for power, thus allowing our study to examine the differences in language used in legislative debates.

However, they differ with regards to party polarization. As a two-party system, the United States serves as an example of high polarization. Canada, as a multiparty system, despite recent changes since 2007 (Brady 2014), is recognized in the literature as the epitome of a non-polarized system (Johnston 2015). These differences allow for the exploration of migration topics across two similar political systems that differ with regards to the levels of polarization. Importantly, both are nations founded (largely) by immigrants and are often seen as bastions of hope for those trying to start a new life. Therefore, the two case studies are very different from the European nation-states on which the recent migration literature has focused (Lahav 1997; Odmalm 2011a, 2012). From a practical perspective, two points motivated this case selection because they facilitate comparison. First, Englishspeaking Canada and the USA face many of the same policy issues. Second, both legislatures publish detailed transcripts of debates in English. 
For the United States analysis, we use Gentzkow et al. (2018) Congressional Record for the 43rd-114th Congresses: Parsed Speeches and Phrase Counts data, which captures all floor debates from the United States House of Representatives. We subset the data to include only the House of Representatives' speeches from Winter 1994 to Fall 2016. For the Canadian analysis, we collected debates from the House of Commons from Beelen et al. (2017). We use the OpenParliament.ca PostgreSQL dump provided by Beelen et al. (ibid), which covers speeches from 1994 and trim the US data accordingly. Similarly, we remove speeches in the Canadian data that come after 2016, as this would have no counterpart in the US data. We focus only on the lower houses of the national legislature to maintain comparability across cases. This is necessary as the United States' Senate is an elected body and the Canadian Senate is not. From there, we processed the data into text corpora for analysis. ${ }^{2}$

To better characterize differences in rhetoric on the topics of migration and build a comparison between the United States and Canadian political sectors, we divided parties into "liberal" and "conservative" groups. For the USA, this was straightforward with Democrats as the liberal camp and Republicans the conservative. $^{3,4}$ However, in Canada, the divide is more complicated. In this paper, when we discuss "conservative" parties in Canada, we are referring to the Conservative (C), Canadian Alliance, Progressive Conservative (PC) and Reform parties. Liberal (L), New Democratic Party (NDP) and any successors of the Bloc Quebecois parties all become "liberal." In the USA, this time span includes the Presidencies of Bill Clinton (D), George W. Bush (R), and Barack Obama (D) and the 103rd-114th Congresses within which the majority party changed several times. In Canada, this spans the Campbell (PC), Chretien (L), Martin (L), and Harper (C) Governments, who also represent liberal and conservative blocks in power. Further, this timespan includes migration during the fall of Yugoslavia and ensuing violent conflicts, the genocide in Rwanda, both Desert Storm and Desert Shield/Operation Iraqi Freedom, the September 11, 2001 attacks, the war in Afghanistan, the Arab Spring protests, and the beginning of the Syrian Civil war, the rise of violence in Central America as well as a number of other conflicts.

\footnotetext{
${ }^{2}$ In addition to the high-level overview in the following sections, detailed steps to replicate this data collection process for the United States and Canada is provided in supplemental documentation.

${ }^{3}$ Historically there have been realignments between the parties, which are of interest to the topic of migration generally. However, realignments are not an issue in the time period analyzed in this paper.

${ }^{4}$ For the US data, we kept the independent members of Congress in the dataset but dropped strictly logistical and parliamentary speeches from the data. In the analysis, we are not focusing on the Independent member's speeches as the number of speeches is not representative. For the Canadian data, we dropped all strictly logistical parliamentary speeches from the data as well.

${ }^{5}$ It should be noted that other, smaller parties are also collapsed into the liberal category. All parties that are not Independents (dropped), or included in the conservative grouping, are collapsed into the liberal group.
} 


\subsection{Dataset Subsetting: Dictionary Approach}

To identify migration-related speeches and reduce the size of the corpus in initial analyses, we use a dictionary approach to subset the data. The original US dataset has 377,817 Democratic speeches, 374,397 Republican speeches, and 1840 Independent Speeches. The original Canadian dataset has 231,681 Liberal Party speeches and 172,089 Conservative Party speeches, with a combined 71,068 speeches by other conservative parties. ${ }^{6}$ For the purposes of investigating the outlined research question and particularly for application in the USA and Canadian context, we take a simple approach to subset the corpora of speeches to include only those that are relevant to migration topics. We use a dictionary approach but limit it to three words: asylum, refugee, and immigration. ${ }^{7}$ These words are stemmed along with our corpora and we analyze the speeches that include at least one of these three words relevant to the migration debate in the United States and Canada. ${ }^{8}$ The resulting datasets include 15,547 (5\% of all) and 15,072 (2\% of all) speeches for Canada and the United States, respectively.

\subsection{Structural Topic Modeling}

Existing computational social science literature suggests that political disagreement and issue ownership can be understood by quantitatively analyzing relative emphasis on different terms, ideas, and arguments in political texts (Baum 2012; Lowe 2008; Sakamoto and Takikawa 2018). Based on US legislative data, Gerrish and Blei (2012) outlined legislators' policy positions on specific issues and, using supervised machine learning, explored how the language of laws is correlated with political support. Combining political psychology and machine learning, topic modeling has been applied to the House of Representatives floor speeches to measure member personality traits (Ramey et al. 2016). Hierarchical topic modeling was applied to look at how the Tea Party Republicans relate with regards to their ideal points to the

\footnotetext{
${ }^{6}$ Other parties have: 116,867 (NDP), 64,845 (Bloc Quebecois and related parties), 38,132 (Reform Party), 21,003 (Canadian Alliance), 11,928 (Progressive Conservative), 3573 (Green), 1865 (Independent).

${ }^{7}$ As a robustness check, we conducted the analysis with a much broader dictionary, which delivered similar results. However, a minimalistic version of the dictionary ensures that the speeches we include and topics resulting from the analysis truly belong to a migration-related policy area.

${ }^{8} \mathrm{As}$ an interesting feature of stemming data like ours that focuses on the word refugee, we retain the stem refuge which results in a number of wildlife preservation speeches, especially in the case of the United States where the Arctic National Wildlife Refuge (ANWR) and oil exploration there was of great contest during our time frame of analysis. However, as wildlife refuge issues are not of relevance for the analysis of human migration, we classify wildlife refuge related issues as "irrelevant." In the following section, we explain more on how we coded this and other topics to ensure focus on migration policy-related issues.
} 
remaining of the Republican representatives in Congress (Nguyen et al. 2015). A similar hierarchical modeling approach was used to analyze the political priorities emphasized in US Senate press statements (Grimmer 2010). However, the existing studies have not expanded the computational science approaches to study how issue ownership and policy framing affect legislative debates. To test the aboveoutlined hypotheses, we use unsupervised machine learning techniques, specifically structural topic modeling.

Topic modeling is a non-supervised machine learning technique that allows for the detection of topics in a text corpus that has not been previously manually analyzed and coded. The idea behind topic modeling, in general, is that each word from the text has a certain probability of belonging to a topic and each document represents a mixture of topics (for our purposes a document is a legislative speech). Structural topic modeling allows for the assessment of the role of selected covariates on the latent topics detected through topic modeling. To analyze how political camps frame the migration policy in the legislative speeches, we employ structural topic modeling implemented in $\mathrm{R}$ (2018) in the stm package (Roberts et al. 2017). As we are interested in understanding how topic prevalence (frequency of topic discussed across speeches) and topic content (how a topic is discussed) are affected by the ideological camp to which the politician belongs, stm is the optimal choice of software for this analysis.

The stm package builds on Latent Dirichlet Allocation (Blei et al. 2003) and it also offers the spectral initialization - a non-negative matrix factorization of the word co-occurrence matrix. Following the literature on spectral decomposition with particularly large datasets (more than 10,000 units in the vocabulary), we opt for this approach (Roberts et al. 2017). Using the migration-related subset of the parliamentary speeches, we process the data by removing custom and built-in stop words as well as the words that only appear in one document. We also took the standard steps of case lowering, stemming, and removing punctuation to clean our corpus.

Moreover, using the advantages of the structural topic modeling approach, we specify the interaction effect of the ideological position of the speaker and the date of the speech as the prevalence covariate and ideological position of the speaker as a content covariate. The prevalence covariate allows us to analyze how the selected attributes from the linked metadata effects the contribution of each topic in the documents. The content variable provides the ability to consider how the metadata attributes effect which words are prominent in each topic.

To shed light on the empirical plausibility of the outlined hypotheses, we proceed to develop two models: one for the speeches in the US House of Representative and the other for the speeches in the Canadian Parliament. Both models were defined to include 20 topics. In selecting the number of topics, we tested several other options-providing either a more nuanced or crude understanding of migration policy and relevant subcomponents outlined in the speeches. While stm package offers a technical solution to determining the most informative number of topics, we instead chose the number based on theoretical underpinning. We opt for 20 topics for two reasons. First, it allows a fairly nuanced overview of topic subcomponents 
as the literature suggests are being debated along with the core migration issues (e.g., culture, economy, and security). Second, it also enables us to distinguish a humanitarian subcomponent. The previous work on migration issue ownership largely focuses on the European continent and on economic, cultural, and security aspects of it (Odmalm 2014). The humanitarian aspect, while certainly present in the media and public space, is packaged as the legalistic discussion on the asylum rights and has to an extent been left out in the existing studies focusing on migration policy in the European context. Our model allows us to explore the framing of this part as well.

\subsection{Labeling and Categorizing Topics}

In order to conceptualize the differences between the United States' and Canadian speeches descriptively over the approximately 20 years in our study, we categorize the 20 topics from each of the two country models into six broader-areas or categories that crisscross lenses of issue ownership: the Economy, Culture, Security, Human Rights, Migration Core, and Irrelevant category. This step is necessary as unsupervised machine learning does not guarantee interpretable results that are comparable across corpora. More concretely, one raw topic from the Canadian corpus is not directly comparable to another raw topic in the USA without human interpretation and validation to ensure the topics are reasonably alike. The grouping stage by human coders accomplishes this goal. We categorize the model outputs for both countries based on the most frequent policy areas that the models found. While descriptive in nature, these summary statistics allow us to draw comparisons between our two cases and better understand the nature of the topics within our data.

To ensure objectivity and coherence between the two countries, while taking into account case study expertise of the team working on this paper, each topic was coded by two of the three authors. If the coding differed, the third author (and case study expert) adjudicated and assigned the final label. ${ }^{9}$

\section{Results}

We divide the results section into four parts. We first outline the 20 topics our model has produced to give readers a better understanding of the data we analyzed. Second, we analyze which migration-related topics can be associated with either of the two ideological camps. Here, we disregard time and focus on the entire dataset. Third, we focus on the changes in topic salience across time for a number of theoretically relevant topics. Fourth, we focus on understanding how parties frame

\footnotetext{
${ }^{9}$ Marcella Morris for the USA and Tyler Amos for Canada.
} 
migration policy through the selection of representative keywords from individual speeches. Each of these steps allows for the testing of our hypotheses from a different perspective. For each of the steps, we start with the United States, which we then compare with Canada.

\subsection{Topics in the USA and Canada}

Figure 1 shows the number or count of topics that we coded under broader categories of the Economy, Culture, Security, Human Rights, Migration Core, and Irrelevant topics. Within the Migration Core category, across both cases, we see topics related to acts of immigration by humans crossing borders and the law enforcement efforts involved in border protection but also the legal parameters lawmakers wrestle

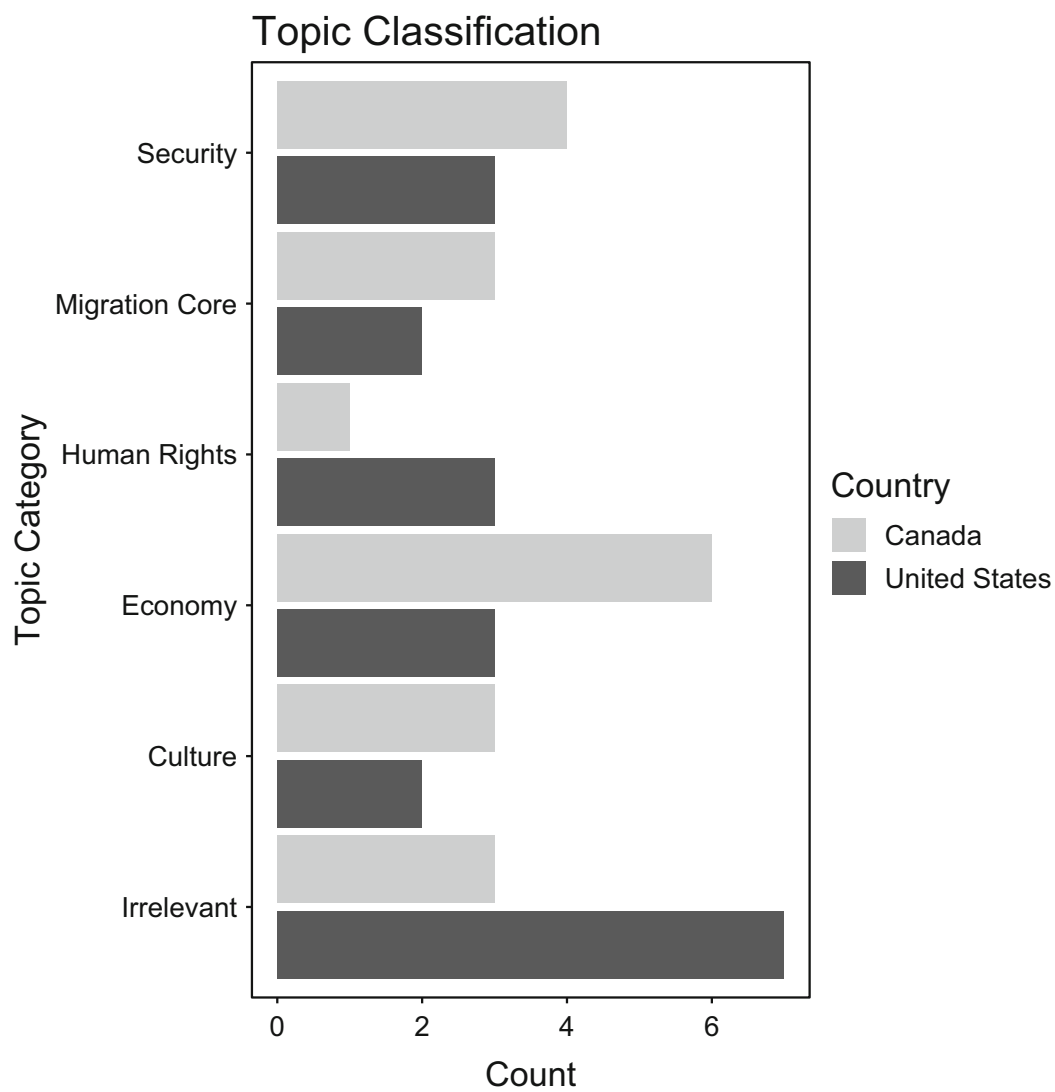

Fig. 1 Topic categorization: migration subsample for the US House of Representatives and the Canadian House of Commons (1994-2016) 
with, such as regulation of visas and requirements for citizenship. Within the economic topics, we categorize budget, welfare programs, ${ }^{10}$ international trade, job programs, and infrastructure type topics which arise as a feature of the discussions about the impact of immigration. Under Culture, we find topics related to welfare, religion, aspirational descriptions of citizenship, multiculturalism, and the legacy of immigration for the national identity. The Security and Human Rights categories are clearer than some of the others. For Security, we include the topics that focus on terrorism, international conflicts, or wars, while Human Rights includes topics that include humanitarian aid, violence against women, and refugee rights.

It should be noted that we categorized a number of topics as "Irrelevant." This category mostly includes topics comprised of parliamentary speech and procedural language required by the chambers from which the speeches originate. ${ }^{11}$

Table 1 presents the 20 topic outputs for the United States and Canada along with the coding into broader categories. Asterisks are used to denote truncated words. We stemmed our corpora in order to better match words, here illeg* indicates the dictionary would include all words that include the root of illeg, regardless of its ending thus including both illegal, illegally, and illegals in our data with only one dictionary entry. We list the topics in the same order as the model produced them, making it easier for the readers interested in replicating our steps to also follow our coding of the topics. In the following pages, we unpack these differences more through the lens of ideological camps, but the differences in the raw data provide helpful context to the broad questions we tackle, as there are clear differences between the two countries, their politics, and debates.

In addition to the coding scheme used to group topics produced by the model in six broader categories, Fig. 2a, b list topics according to their proportion across speeches. In the next section, we present differences in topic salience between ideological camps in the USA and Canada.

\subsection{Topic Association by Ideological Block}

We first focus on topic prevalence in the US House of Representatives. It answers the question which migration-related topics are associated with the Democrats or Republicans. Out of the 20 topics from the model, we coded a number of them as irrelevant for the analysis - having mostly been dealing with the procedural aspects of the parliamentary debates. ${ }^{12}$ Keeping the time component of the structural topic model fixed, we first analyze which migration-related topics the two US parties

\footnotetext{
${ }^{10}$ The economic welfare programs comprise spending and job training programs from a budgetary perspective while cultural welfare topics include social safety-net-type programs.

${ }^{11}$ We include the wildlife refuge topics which were present in the United States' and Canadian topics in the "Irrelevant" category.

${ }^{12} \mathrm{~A}$ list of topics and words available in Table 1a, b.
} 
Table 1 STM topic output and classification

\begin{tabular}{|c|c|c|c|}
\hline No. & Label & $\begin{array}{l}\text { Topic output (marginal highest } \\
\text { probability output) }\end{array}$ & Category \\
\hline \multicolumn{4}{|c|}{ (a) United States } \\
\hline 1 & Immigration types & $\begin{array}{l}\text { immigr*, illeg*, countri*, legal, american, } \\
\text { will, state, come, unit, law, citizen, famili*, } \\
\text { reform, visa, system, million, nation, } \\
\text { citizenship, children, status }\end{array}$ & Migration Core \\
\hline 2 & Law enforcement & $\begin{array}{l}\text { law, enforc*, feder*, state, alien, crimin*, } \\
\text { local, crime, immigr*, offic*, illeg*, depart, } \\
\text { justic*, polic*, communiti*, will, citi*, case, } \\
\text { deport, attorney }\end{array}$ & Migration Core \\
\hline 3 & Procedural 1 & $\begin{array}{l}\text { gentleman, yield, thank, texa*, california, } \\
\text { madam, consum*, act, rank, subcommitte, } \\
\text { gentlewoman, judiciari*, minut*, bipartisan, } \\
\text { may, balanc*, reform, chair, distinguish, } \\
\text { section }\end{array}$ & Irrelevant \\
\hline 4 & Wildlife refuge & $\begin{array}{l}\text { refug*, nation, land, wildlif*, park, area, } \\
\text { protect, water, will, servic*, forest, state, fish, } \\
\text { feder*, conserv*, acr*, manag*, resourc*, } \\
\text { public, legisl* }\end{array}$ & Irrelevant \\
\hline 5 & Voting & $\begin{array}{l}\text { presid }^{*}, \text { vote, constitut*, congress, law, court, } \\
\text { elect, execut*, state, power, action, act, will, } \\
\text { voter, suprem*, senat*, right, obama, district, } \\
\text { branch }\end{array}$ & Culture \\
\hline 6 & Multicultural America & $\begin{array}{l}\text { american, nation, state, communiti*, world, } \\
\text { unit, histori*, honor, asian, america, great, } \\
\text { countri*, first, freedom, serv*, day, contribut*, }^{*} \text {, } \\
\text { pacif*, live, island }\end{array}$ & Irrelevant \\
\hline 7 & Human trafficking & $\begin{array}{l}\text { women, violenc*, victim, protect, act, state, } \\
\text { right, will, abus*, administr*, domest*, } \\
\text { american, report, traffick*, terrorist, crime, } \\
\text { countri*, human, one, kill }^{*} \text {, }\end{array}$ & Human rights \\
\hline 8 & Foreign aid & $\begin{array}{l}\text { million, fund, assist, provid*, program, } \\
\text { include*, aid, state, intern, will, increas*, } \\
\text { billion, effort, request, help, develop, countri*, } \\
\text { foreign, guam, appropri* }\end{array}$ & Human rights \\
\hline 9 & Procedural 2 & $\begin{array}{l}\text { one, say, will, countri*, great, thing, state, } \\
\text { serv*, life, talk, nation, come, live, district, } \\
\text { famili*, now, citi*, school, first, honor }\end{array}$ & Irrelevant \\
\hline 10 & Security & $\begin{array}{l}\text { secur*, border, homeland, depart, nation, } \\
\text { terrorist, will, protect, need, fund, agent, state, } \\
\text { agenc*, patrol, guard, intellig*, terror, } \\
\text { commiss*, enforc*, attack }\end{array}$ & Security \\
\hline
\end{tabular}


Table 1 (continued)

\begin{tabular}{|c|c|c|c|}
\hline No. & Label & $\begin{array}{l}\text { Topic output (marginal highest } \\
\text { probability output) }\end{array}$ & Category \\
\hline 11 & Procedural 3 & $\begin{array}{l}\text { say, dont, now, come, thing, one, talk, will, } \\
\text { job, back, countri*, got, american, that, look, } \\
\text { america, let, happen, money, tri* }\end{array}$ & Irrelevant \\
\hline 12 & Budget & $\begin{array}{l}\text { republican, tax, budget, will, american, cut, } \\
\text { care, health, billion, pass, spend, democrat, } \\
\text { congress, reform, pay, major, vote, money, job, } \\
\text { cost }\end{array}$ & Economy \\
\hline 13 & Oil production & $\begin{array}{l}\text { energi*, oil, gas, drill, will, price, percent, } \\
\text { nation, state, need, product, use, develop, } \\
\text { water, environment, increas*, million, } \\
\text { compani*, american, arctic* }\end{array}$ & Economy \\
\hline 14 & Procedural 4 & $\begin{array}{l}\text { amend, chairman, rule, provis, will, act, } \\
\text { requir*, appropri*, fund, languag*, state, } \\
\text { legisl*, provid*, offer, debat*, author, process, } \\
\text { report, confer*, member }\end{array}$ & Irrelevant \\
\hline 15 & Education & $\begin{array}{l}\text { educ*, school, will, america, children, state, } \\
\text { one, american, need, unit, student, law, come, } \\
\text { nation, number, million, now, countri*, } \\
\text { problem, place }\end{array}$ & Culture \\
\hline 16 & International conflicts & $\begin{array}{l}\text { state, unit, peac*, war, will, world, nation, } \\
\text { israel, presid*, forc*, militari*, must, refuge*, } \\
\text { countri*, resolut*, genocid*, now, intern, one, } \\
\text { continu* }\end{array}$ & Security \\
\hline 17 & Threats & $\begin{array}{l}\text { border, iraq, state, mexico, drug, unit, war, } \\
\text { militari*, will, come, troop, patrol, } \\
\text { afghanistan, one, mexican, illeg*, forc,* } \\
\text { nation, iraqi, soldier }\end{array}$ & Security \\
\hline 18 & Welfare & $\begin{array}{l}\text { program, children, state, health, educ*, care, } \\
\text { will, provid*, need, famili*, percent, worker, } \\
\text { child, school, benefit, food, servic*, employ, } \\
\text { help, english }\end{array}$ & Economy \\
\hline 19 & Humanitarianism & $\begin{array}{l}\text { refuge*, human, right, state, unit, china, haiti, } \\
\text { vietnam, religi*, freedom, will, polici*, } \\
\text { countri*, cuba, persecut*, cuban, polit*, } \\
\text { democraci*, haitian, asylum }\end{array}$ & Human rights \\
\hline 20 & Procedural 5 & $\begin{array}{l}\text { will, legisl*, american, opportun*, believ*, } \\
\text { need, america, hope, colleagu*, trade, abl*, } \\
\text { deal, good, issu*, countri*, state, forward, } \\
\text { agreement, problem, congress }\end{array}$ & Irrelevant \\
\hline
\end{tabular}


Table 1 (continued)

\begin{tabular}{|c|c|c|c|}
\hline No. & Label & $\begin{array}{l}\text { Topic output (marginal highest } \\
\text { probability output) }\end{array}$ & Category \\
\hline \multicolumn{4}{|c|}{ (b) Canada } \\
\hline 1 & Budget & $\begin{array}{l}\text { conserv*, liber*, will, prime, budget, elect*, } \\
\text { parti*, money, cut, public, now, chang*, job, } \\
\text { one, say, vote, tax, promis*, polit*, noth* }\end{array}$ & Economy \\
\hline 2 & Humanitarianism & $\begin{array}{l}\text { refuge*, humanitarian, syrian, help, assist, } \\
\text { million, will, countri*, syria, need, provid*, } \\
\text { aid, intern, crisi*, communiti*, situat*, effort, } \\
\text { region, resettl*, organ* }\end{array}$ & Migration Core \\
\hline 3 & First nations & $\begin{array}{l}\text { nation, will, aborigin*, land, first, agreement, } \\
\text { treati*, protect, water, environ*, environment, } \\
\text { throne, act, speech, area, park, territori*, } \\
\text { develop, chang*, climat* }\end{array}$ & Irrelevant \\
\hline 4 & Procedural 1 & $\begin{array}{l}\text { will, member, parti*, opposite*, parliament, } \\
\text { debat, vote, legis }{ }^{*}, \text { reform, report, liber*, } \\
\text { stand, consult, ask, made, amend, act, day, } \\
\text { elect, say }\end{array}$ & Irrelevant \\
\hline 5 & Immigration types & $\begin{array}{l}\text { immigr*, citizenship, applic*, famili*, } \\
\text { canadian, resid*, process, foreign, worker, } \\
\text { countri*, system, program, will, come, } \\
\text { temporari*, perman*, visa, citizen, number, } \\
\text { offic* }\end{array}$ & Migration Core \\
\hline 6 & Citizenship & $\begin{array}{l}\text { act, court, citizenship, law, right, legisl,* } \\
\text { canadian, amend*, will, citizen, case, charter, } \\
\text { person, process, chang*, one, decis*, rule, } \\
\text { claus*, may }\end{array}$ & Culture \\
\hline 7 & Welfare & $\begin{array}{l}\text { women, health, care, poverti,* need, senior, } \\
\text { program, will, social, live, hous*, medic*, } \\
\text { equal, system, incom*, feder*, provinc*, } \\
\text { servic*, access*, countri* }\end{array}$ & Economy \\
\hline 8 & Law enforcement & $\begin{array}{l}\text { crimin*, crime, victim, will, justic*, law, } \\
\text { sentenc*, offenc*, serious, marriag, women, } \\
\text { person, commit, forc*, deport, act, polic*, } \\
\text { protect, legisl*, violenc* }\end{array}$ & Security \\
\hline 9 & Provincial concerns & $\begin{array}{l}\text { quebec, feder*, provinc*, languag*, bloc, will, } \\
\text { french, nation, offici*, one, cultur*, popul*, } \\
\text { constitut*, québécoi*, must, provinci*, } \\
\text { jurisdict*, francophon*, canadian, recogn* }\end{array}$ & Culture \\
\hline 10 & Asylum process & $\begin{array}{l}\text { refuge*, countri*, system, immigr*, claim, } \\
\text { appeal, will, claimant*, protect, process, } \\
\text { status, decis*, asylum, board, case, determin*, } \\
\text { arriv*, need, divis*, safe }\end{array}$ & Migration Core \\
\hline
\end{tabular}


Table 1 (continued)

\begin{tabular}{|c|c|c|c|}
\hline No. & Label & $\begin{array}{l}\text { Topic output (marginal highest } \\
\text { probability output) }\end{array}$ & Category \\
\hline 11 & History of immigration & $\begin{array}{l}\text { canadian, countri*, communiti*, world, } \\
\text { nation, histori*, one, great, cultur*, immigr*, } \\
\text { day, proud, first, divers*, societi*, contribut*, } \\
\text { valu*, recogn*, will, live }\end{array}$ & Culture \\
\hline 12 & Family support & $\begin{array}{l}\text { famili, children, tax, child, parent, live, } \\
\text { communiti*, young, ride, will, home, school, } \\
\text { help, one, care, incom*, pay, need, centr*, } \\
\text { member }\end{array}$ & Economy \\
\hline 13 & Investment in Jobs & $\begin{array}{l}\text { will, program, budget, tax, need, job, invest, } \\
\text { econom*, economi*, fund, plan, help, busi*, } \\
\text { billion, provid*, increas*, million, feder*, } \\
\text { employ, benefit }\end{array}$ & Economy \\
\hline 14 & Privacy or security & $\begin{array}{l}\text { inform, will, act, canadian, privaci*, public, } \\
\text { servic*, person, census, data, state, use, } \\
\text { provid*, air, passeng*, access, may, legisl*, } \\
\text { concern, one }\end{array}$ & Security \\
\hline 15 & Human trafficking & $\begin{array}{l}\text { human, right, intern, traffick*, protect, } \\
\text { countri*, smuggl*, will, immigr*, exploit*, } \\
\text { organ*, freedom, include*, trade, abus*, } \\
\text { convent*, victim, smuggler, crimin*, law }\end{array}$ & Human rights \\
\hline 16 & Economic sectors & $\begin{array}{l}\text { industri*, will, trade, agricultur*, product, } \\
\text { region, communiti*, farmer, ride, compani*, } \\
\text { provinc*, job, agreement, atlant*, busi*, area, } \\
\text { coast, sector, island, nova }\end{array}$ & Economy \\
\hline 17 & Security & $\begin{array}{l}\text { secur*, border, state, will, terrorist, unit, } \\
\text { terror, agenc*, nation, offic*, safeti*, } \\
\text { american, organ*, custom, canadian, } \\
\text { septemb*, need, protect, rcmp, polic* }\end{array}$ & Security \\
\hline 18 & International conflicts & $\begin{array}{l}\text { will, forc*, war, militari*, peac*, must, intern, } \\
\text { mission, world, nation, canadian, conflict, } \\
\text { state, secur*, unit, iraq, afghanistan, action, } \\
\text { countri*, nato* }\end{array}$ & Security \\
\hline 19 & Procedural 2 & $\begin{array}{l}\text { countri*, one, say, come, talk, thing, will, } \\
\text { look, problem, need, deal, happen, back, tri*, } \\
\text { someth*, good, realli*, colleagu*, ask, kind }\end{array}$ & Irrelevant \\
\hline 20 & International trade & $\begin{array}{l}\text { trade, countri*, intern*, polici*, canadian, } \\
\text { develop, will, world, foreign, econom*, } \\
\text { depart, per, agreement, cent*, state, unit, must, } \\
\text { interest, canada, global }\end{array}$ & Economy \\
\hline
\end{tabular}


(a) Top Migration Topics in the US Congress

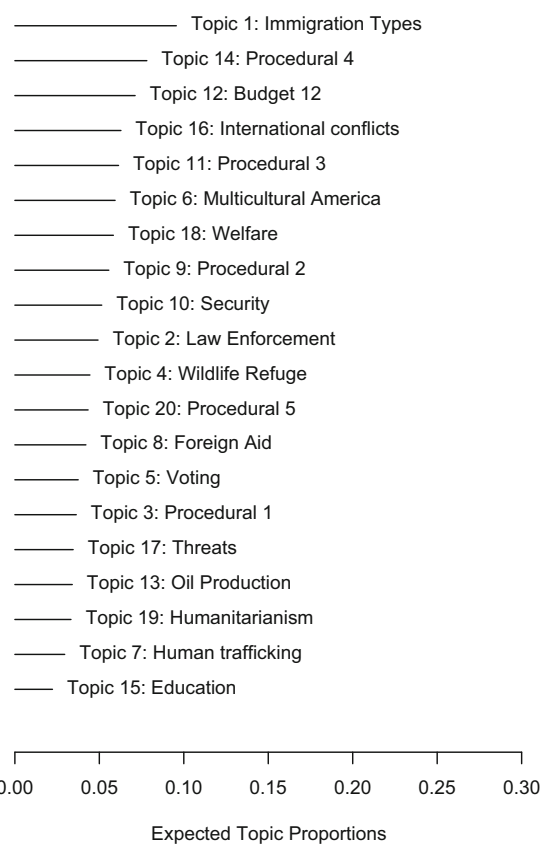

(b) Top Migration Topics in the Canadian House of Commons

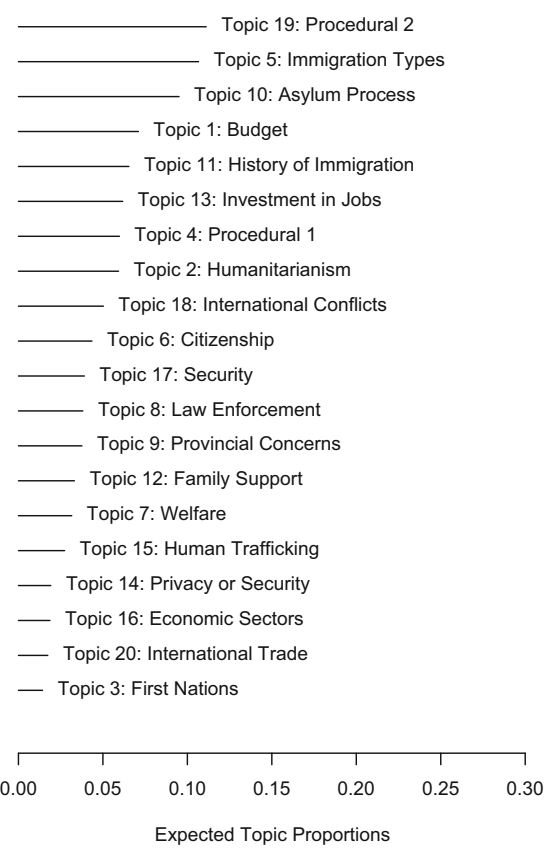

Fig. 2 Expected migration-related topics proportion legislative speeches in the US Congress and Canadian House of Commons. (a) Top migration topics in the US Congress. (b) Top migration topics in the Canadian House of Commons

emphasize. Figure 3a provides a visualization of the expected topic prevalence contrasted for Republicans and Democrats-excluding topics coded as irrelevant. The sequence of the topics follows the categorization introduced in the previous subsection and allows comparison across two cases-from Migration Core, Security, Economy, Culture to Human Rights. Republicans dominate the discussions on the types of immigration, law enforcement, security, and threats when compared to Democrats. Budgetary aspects, use of resources, and international conflicts fall more on the side of the Democrats. Both parties emphasize equally multiculturalism in the USA, welfare, and education aspects of migration.

In Canada, we see a similar picture with differences in the topic association being smaller between the two blocks (see Fig. 3b). Topics such as immigration type and legal aspects of migration policy, which we classified in the Migration Core area, fall between the two ideological blocks. Moreover, humanitarianism, human trafficking, security, and international conflicts are equally associated with liberals and conservatives. A number of topics, traditionally owned by liberals, such as budget, welfare, and family support topics are indeed more strongly associated with liberals. Historical migration with an emphasis on Canadian multicultural nation 
(a) Migration Topics in the US Congress

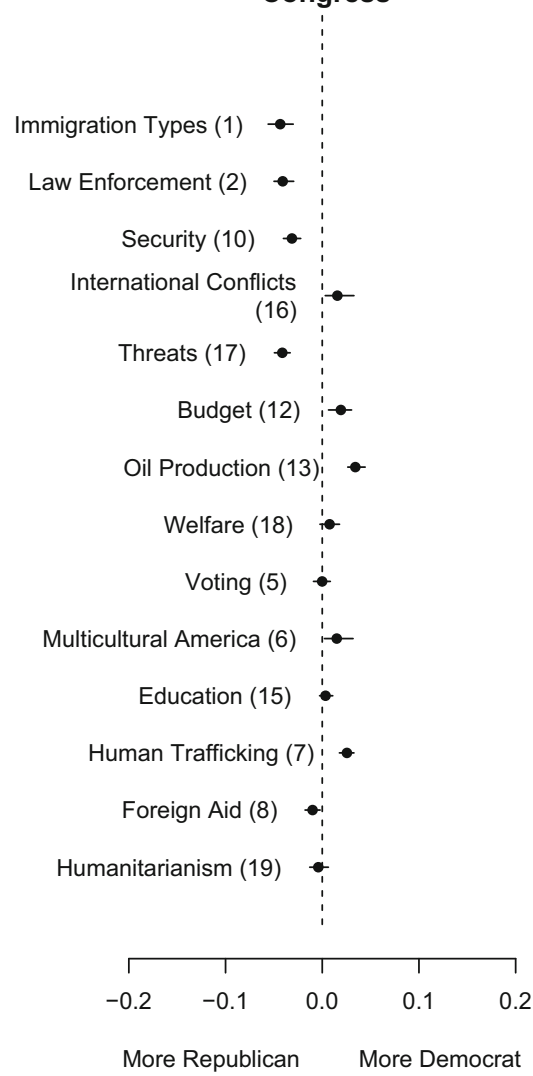

(b) Migration Topics in the Canadian Parliament

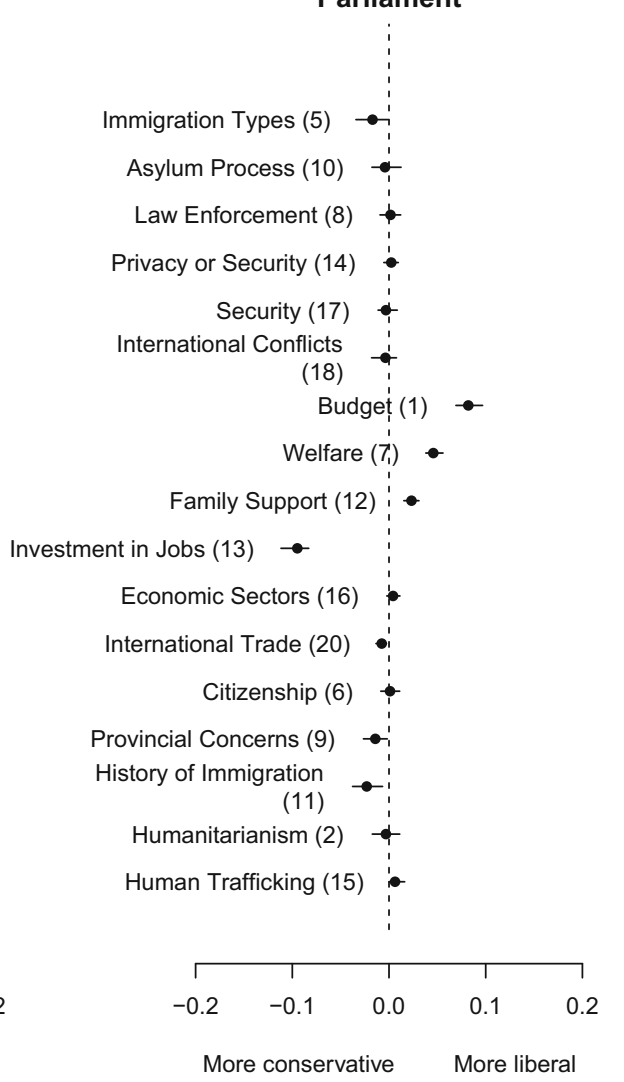

Fig. 3 Expected Migration-related Topics Proportion between Parties in the US House of Representative and the Canadian House of Commons. The coefficients refer to the expected topic proportion of the text corpus determined as a function of the selected variables. In this case, the topic prevalence for each of the migration-related topics is contrasted for two parties, Republicans and Democrats. (a) Top migration topics in the US Congress. (b) Top migration topics in the Canadian Parliament

and debates on jobs fall to the side of the conservatives. We see a contrast in the budget and jobs topics association-while the budget aspect of the migration is more salient for liberals, the jobs aspect is more associated with conservatives. Topic association in both the USA and in Canada is aligned with our hypotheses. Ideological camps tend to emphasize more subcomponents of migration policy over which they traditionally have ownership over. We also show that, as expected, the differences in the topic association are, due to weaker polarization, smaller in Canada than in the USA. 


\subsection{Topic Prevalence Across Time}

Figure 4 illustrates how House members in the United States discussed migration topics from 1994 to 2016 . To understand how the emphasis of the migration-related topic changes across time, we select four topics - two topics from the core migration area, one topic representing issues traditionally owned by Democrats, and one by Republicans. The four selected topics are the following: an immigration type topic, an immigration enforcement topic, a security-related topic, and a human trafficking topic. ${ }^{13}$ For each of these topics, we analyze how topic prevalence has changed across time and party.

First, we focus on the types of immigration topic. The topic deals with different types of immigration from the perspective of legality, legal status, and procedures immigrants go through. Change in topic prevalence over time is visualized in Fig. 4 Three peaks are visible in the period between 1994 and 2016. The first peak occurred in the late 1990s, in parallel to the aftermath of the Yugoslav and Rwandan conflicts and during the NATO bombardment of Serbia and Montenegro during the 1999 Kosovo crisis. By the beginning of the 2000s, the topic of immigration types become somewhat less salient, only to return to the House in the 2000s, likely as a result of the rise of the threat of terrorism related to the 9/11 terrorist attack. Both in the late 1990s and in the early 2000s, Republicans emphasized the topic more than Democrats. The last peak in topic salience occurs in 2014, which coincides with the Syrian conflict and moreover with the offensives after the break of Kofi Anan's ceasefire attempt in 2013. While Republicans emphasized discussion of the types of immigration more during the first two peaks, Democrats saw it as more salient in the last period.

The second topic we focus on is migration law enforcement. This topic deals with the violation of the legal framework related to migration and its consequences. After 2001, it becomes a more salient topic in the House of Representative and Republicans emphasize it more. From the law enforcement perspective, 2005 and 2014 represent important points in the timeline.

While both of these topics represent core migration area issues, our US model outlined another subcomponent of the migration topic, which has, to our knowledge, not been discussed extensively in existing studies-human rights or more specifically human trafficking. This topic refers to issues related to crime and abuse, particularly emphasizing women and trafficking crimes. Following our expectations, Democrats appear to own this issue from the mid-1990s through 2015, as they place greater emphasis on this topic. ${ }^{14}$

\footnotetext{
${ }^{13}$ For an overview of the words constituting each topic, consult Table 1a, $\mathrm{b}$.

${ }^{14}$ The change in prevalence on the human trafficking topic from Democrats to Republicans around 2015 may be a feature of the campaigns for the 2016 Presidential election, the increased migration (or focus on migration) as a result of the Central American crises or another set of issues. Future work could explore such changes over time in more detail.
} 

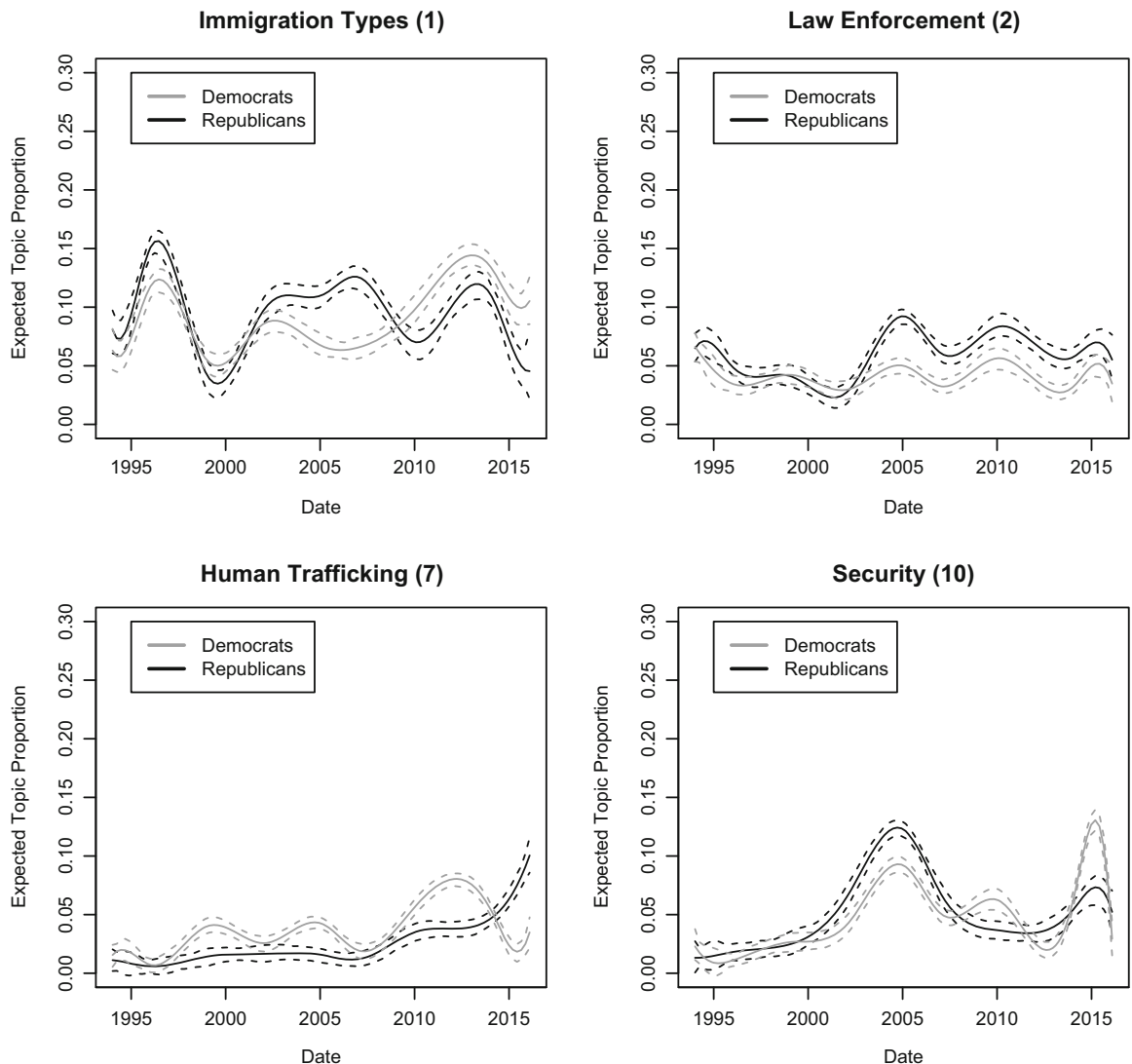

Fig. 4 Migration-related Topics Association between Parties in the US House of Representatives (1994-2016). We report the expected topic proportion not simply topic proportion, because it is an approximation based on the default STM settings-incorporation of uncertainty in proportion estimates via the method of composition (Roberts et al. 2017)

We now turn our attention to the security graph in Fig. 4 as a subcomponent along which migration policy is often discussed. This topic refers to border protection as well as security issues like terrorism. Security is an issue traditionally associated with Republicans, which can also be seen in Fig. 4's Security panel that illustrates the security topic from our US model. Republicans emphasize the security topic more until the second part of the 2000s when it becomes more salient for Democrats.

Using the same theoretical approach for Canada as for the US model, we again select four topics to include two core migration area topics, one issue traditionally owned by liberals and one owned by conservatives. Moreover, the selected topics are also similar content-wise to the topics selected for the US case, thus facilitating a comparative case study approach. The selected topics are the following ones: 

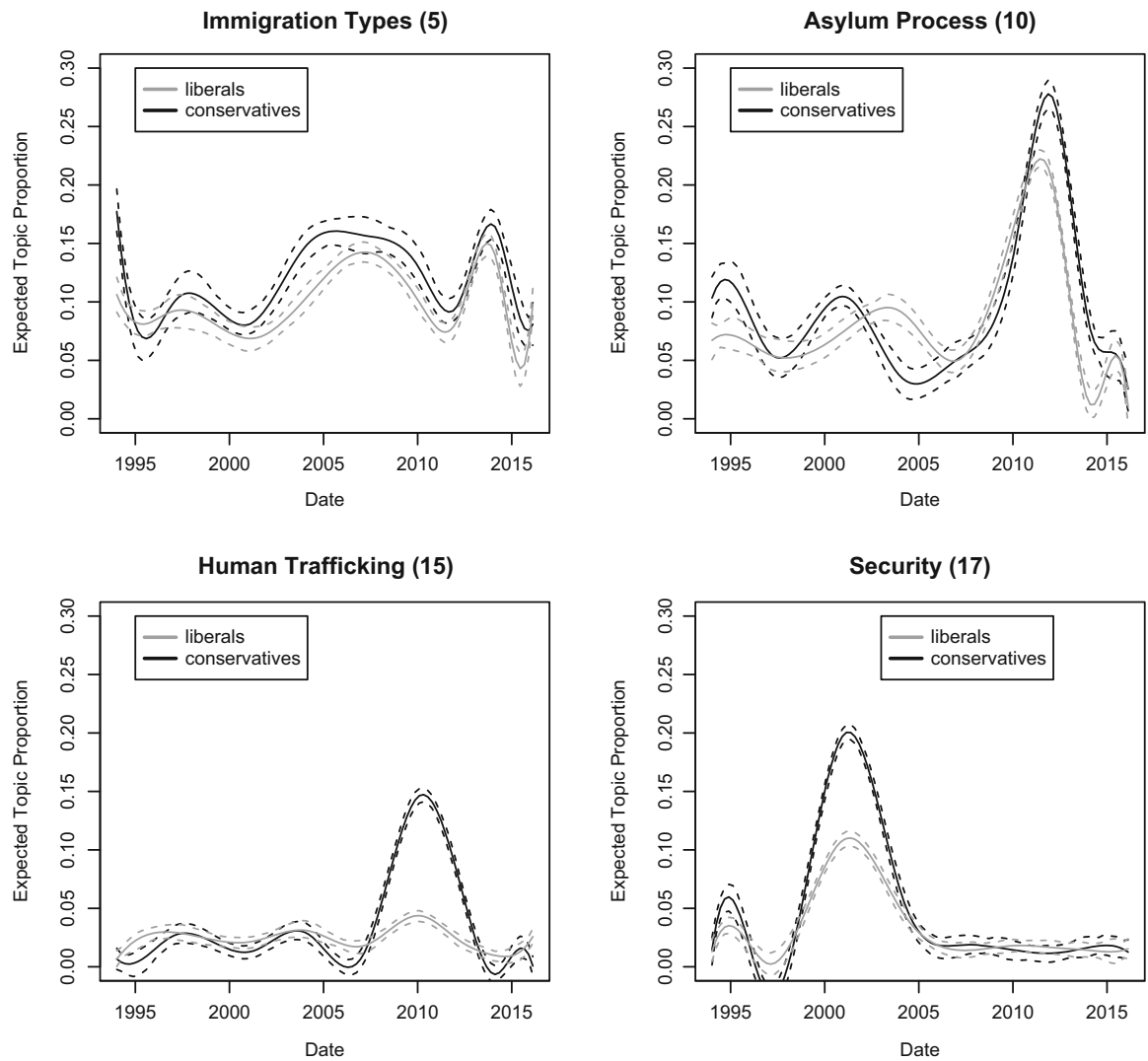

Fig. 5 Migration and Migration-related Topics across Time in the Canadian House of Commons

an immigration type topic, an asylum-process-related topic, a human trafficking topic, ${ }^{15}$ and a security-related topic (see Fig. 5).

As expected by our hypotheses, the contrast in migration-related topic prevalence between the two Canadian political camps appears smaller than between the USA political camps across time. There are some periods where trends for the two groups of parties diverge, notably with respect to asylum and security, but overall both parties display quite similar trends. This contrasts with the American case where with the human trafficking topic, for example, the Democrats' topic prevalence trend is completely different from the Republicans'. When there are differences in emphasis, the two ideological camps emphasize an issue that they are traditionally considered to own (e.g., conservatives with security), just as our hypotheses suggest.

\footnotetext{
${ }^{15}$ An explanation for the spike in conservative discourse on the Human Trafficking topic around 2010 is not readily apparent based on our current reading of the relevant literature. Future work could explore such anomalies in more detail.
} 
Analysis of both US and Canadian topics across time also shows that differences in prevalence fluctuate over time. While the interpretation of the reversals surpasses the scope of this chapter, the literature suggests that framing strongly depends on the external events and the salience of the topic in the public discourse (Lefevere et al. 2017). We suggest the fluctuations could be a result of pertinent legislative acts, important political events, and majorities in the lower houses of the legislative bodies in the USA and Canada.

\subsection{Migration Policy Framing: Word Use}

In the earlier two subsections, we discussed how the two ideological blocks quantitatively contribute to the migration topics, first by taking the whole dataset into account and then by emphasizing the changes across time. In this subsection, we focus on the results from the perspective of how the two ideological blocks discuss migration policy. We will analyze the choice of the words liberal as opposed to conservative camps uses-providing an in-depth understanding of the framing strategies. Figure $6 \mathrm{a}, \mathrm{b}$ are visualizations of the word choice comparisons we present in this section. They represent the types of words from the Human Trafficking topic from the United States' and Canadian Speeches, respectively. We provide visualizations for the other topics in the appendix. We first analyze how Republicans and

(a) US Human Trafficking (7)

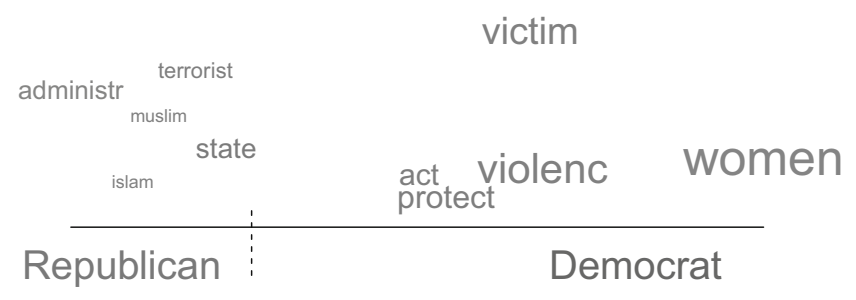

(b) Canada Human Trafficking (15)

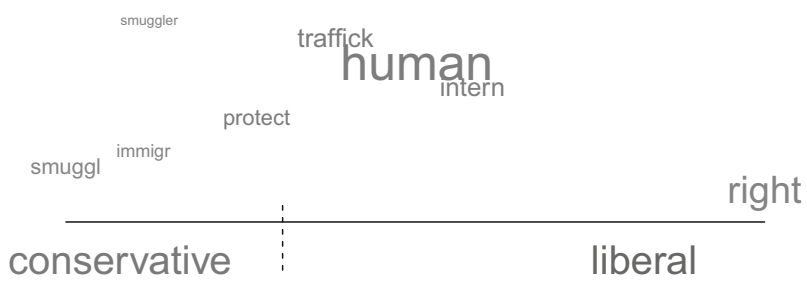

Fig. 6 Word choice comparison plot for Human Trafficking topic. (a) US. (b) Canada 
Democrats in the US House of Representatives discuss migration-related topics. ${ }^{16}$ With regard to types of immigration, Republicans emphasize "illeg," "american," and "state" while Democrats emphasize "immigr*" and "family." Similarly, when discussing enforcement of immigration policy, Republicans emphasize "illeg," "alien," "crime," "criminal," and "immigr" whereas Democrats emphasize "local" and "offic*". We interpret this as the parties framing policies by leaning into migration umbrella issues they own. In this case, Republicans own law enforcement and crime. This supports Odmalm's (2011a) theoretical approach, which suggests parties' debate migration policy in ways which allows them to avoid competences of their opponents and focus on their strengths.

The topic of human rights issues, with a specific focus on women's rights and rights of refugees, is another interesting case. When discussing gender-based violence, Democrats use words such as "victim," "women," "violence," "traffick*”, "domes*”, "abuse," as well as "protect," "right," and "act.” Republicans emphasize "islam," "terrorist," "muslim," as well as "american" and "kill." In this context, Republicans appear to emphasize perceived threats, while Democrats appear to be adopting a women's rights lens - areas which play to their perceived issue ownership. When discussing geography with respect to Human Rights, Democrats emphasize more cases in which refugees are entitled to protection-using words such as "haiti" or "haitian." Republicans use a vocabulary of Human Rights to discuss the countries with authoritarian systems of government, such as Cuba and China. Both parties equally emphasize freedom.

Considering the topic of security, Republicans frame the policy to outline their ownership over it-they emphasize "secur*", "terrorist," and "nation," while Democrats speak about the procedural issues related to the border, such as "fund*" and "agent*". The topic of threats is discussed within the frame of "border*", "patrol," "illeg*", and "Mexico," while Democrats talk about "troops" and "militari*", in connection to Iraq and Afghanistan. The most striking is the topic of international conflicts, where Democrats focus on "peac*", while Republicans discuss "war," "militari*", and "Iraq."

Culture as one of the topics often emphasized as part of the broader migration theme is also represented in parliamentary speeches. Both Republicans and Democrats emphasize "nation" in this context, but Republicans talk about "great*", "freedom*", and "serv*", while Democrats emphasize "communiti*", "histori*", as well as "asian" and "pacif*". Our interpretation is that Democrats emphasize the multicultural aspect of the USA as a country founded by immigrants, while Republicans emphasize the role of freedom and its role in the American culture. On economic topics, Republicans discuss the budget in relation to taxation and spending on healthcare, while the Democrats refer more explicitly to "cuts," "budget," and "republican," perhaps referring to tax or spending cuts Republicans are introducing.

\footnotetext{
${ }^{16}$ See the online Appendix for a graphical illustration of this point.
} 
Now turning to the Canadian context, we analyze how conservatives and liberals frame migration-related topics. In Canada, with regard to legal aspects of immigration, conservatives emphasized: "citizenship" and "canadian*", while liberals focused on "immigr*", "applic*", and "process." When discussing the security subcomponent of migration policy, liberals focused on "secur*" and "border*", while the conservatives emphasize "terrorist*". We analyze this framing with our theoretical approach in mind-conservatives tend to emphasize issues which they own, such as security and protection from terrorism, but compared to the USA, there is a weaker distinction between liberals and conservatives with respect to their framing of migration discussions.

As in the USA, the issue of human rights, with a specific focus on human trafficking is also outlined in our Canadian model. When discussing this topic, conservatives emphasize the connection between "immigr*" and "smuggl*", while liberals emphasize "human*", "traffick*" and "right" (see Fig. 6b). We suggest that also here we can identify patterns of framing based on issue ownership. For liberals, the focus is on trafficking, victims, and their rights, while conservatives dedicate more attention to the crime of smuggling in connection with immigration. However, the differences are not as striking as in the USA between Republicans and Democrats. When discussing humanitarian aspects of migration, conservatives emphasize "syria*", "syrian*”, "help," "humanitarian," and "assist," while for liberals it is more about "refuge*".

Similar again to the USA, the culture topic that emerges from our Canadian model seems to revolve around the multicultural origins of Canada and diversity of the origins of its inhabitants. However, there are no clear differences in the framing of this subcomponent between the two blocks. Conservatives emphasize "canadian" and "histori*", while for liberals the focus is on "community," "nation," and "great*", all of which also occur in the US debates.

Finally, migration-related economic topics are of great importance in the Canadian model. When discussing the labor market, conservatives use words such as "job", "plan," and "econom*". For liberals, the emphasis is more on "budget," "invest*", "tax," "program," and "need." Differences in policy framing are perhaps clearer when considering the aspect of welfare, where the conservatives focus on "tax," "incom*”, and "pay," while liberals emphasize "famili*", "children," "child," "parent," and "communiti*".

Analysis of the differences between the two ideological blocks in word use within topics confirmed our expectations. In the USA, there are clear differences in the framing of the migration-related issues. When forced to discuss migration policy_over which neither block has clear issue ownership_-political elites' choice of words implies policy framing in a way that allows them to emphasize the subcomponent they have established ownership over. We find this pattern both in the USA and in Canada but the issue ownership differences in word choice are more pronounced in the USA than in Canada. In the next section, we briefly summarize our findings and conclusions. 


\section{Conclusion}

The chapter explored how ideological camps in the USA and Canada discuss migration policy in legislative speeches. We argued that political camps tend to avoid discussing migration directly as it represents a political cleavage encompassing multiple, opposing issues over which lines of ideological ownership are not yet clearly drawn. Modeling parliamentary discourse as an area where politicians sandbox their ideas, we explored how political camps frame migration policy in their speeches.

Our analysis showed that politicians in the USA and Canadian legislatures debate migration policy in a way that allows them to emphasize migration aspects over which their parties traditionally hold issue ownership. Specifically, our results confirmed that Democrats in the USA and the liberals in Canada, in their migrationrelated legislative speeches, stress issues they own-such as poverty, welfare, weapons control, and health. In contrast, US Republicans and Canadian conservatives instead focus on the external threats, security, and sovereignty aspects of migration policy as issues they traditionally own.

Our results suggested that parties not only emphasize the issues they own more, they also frame migration in a way that emphasizes their competences over subcomponents of the broader policy area. Republicans and conservatives frame subcomponents of migration such as humanitarianism in a way that emphasizes issues traditionally owned by their political camp. Democrats and liberals do the same-they frame migration policy by focusing the debate on their strengths, even when discussing security threats for which their competition can be considered as more competent.

Through our focus on differences in polarization between the case studies, we also found evidence that the differences in migration policy framing between the two political camps are more pronounced in the USA than in Canada. The chapter contributes to the existing migration policy literature by expanding the research on legislative speeches in the USA and Canada, two cases which have not yet been explored in this context. By showing that political actors tend to emphasize issues they own more in a polarized context, we expanded the research on the effects of polarization on policy framing in legislative speeches.

Our exploratory study of migration framing in legislative debates in the USA and Canada has also enabled a better understanding of humanitarian subcomponent of migration issues. While the humanitarian migration subcomponent is present in the public discourse, the existing studies, have neglected it, at least thus far. We suggest that future studies should emphasize this aspect of the policy. Particularly, future research could examine how it relates to other, already established components of the migration debate—such as the economy, security, and culture.

The chapter represents a methodological contribution by providing a guide on how automated text analysis and in particular structural topic modeling can be used to study intricate and complex research questions from social sciencessuch as rhetorical conflicts in framing migration policy in legislative speeches. Further extensions of this work should incorporate validation of the findings either 
through human coding of a part of the selected dataset or through comparison with existing qualitative studies. Expanding the time frame, and therefore incorporating more international conflicts, may clarify the relationship between conflict abroad and policy framing by domestic political elites. We hope this chapter encourages more researchers to use quantitative text analysis to explore social science research puzzles.

Acknowledgments The authors would like to acknowledge and thank the BIGSSS Computational Social Science Summer School on Conflict, Jacobs University, and the Volkswagen Foundation, which funded the program for the support and training to make this project possible. Additionally, we would like to thank the Department of Government Research Seminar at the University of Vienna for their thoughtful feedback on a draft of this paper as well as Gray Barrett for his comments on this project, and finally our appreciation goes to the anonymous reviewers who provided thoughtful direction that improved the final product.

\section{A.1 Appendix}

Supplementary materials, replication code, and links to the relevant datasets are available online.

Repository: www.github.com/tamos/ValuesInText

DOI: https://doi.org/10.5281/zenodo.3242663

\section{References}

Anckar, C. (2008). On the applicability of the most similar systems design and the most different systems design in comparative research. International Journal of Social Research Methodology, 11(5), 389-401. https://doi.org/10.1080/13645570701401552.

Baum, D. (2012). Recognising speakers from the topics they talk about. Speech Communication, 54(10), 1132-1142. https://doi.org/10.1016/j.specom.2012.06.003.

Beelen, K., Thijm, T. A., Cochrane, C., Halvemaan, K., Hirst, G., Kimmins, M., et al. (2017). Digitization of the Canadian parliamentary debates. Canadian Journal of Political Science, 50(3), 849-864. https://doi.org/10.1017/S0008423916001165.

Bélanger, É. (2003). Issue ownership by Canadian political parties 1953-2001. Canadian Journal of Political Science, 36(03), 539-558. https://doi.org/10.1017/S0008423903778755.

Blei, D. M., Ng, A. Y., \& Jordan, M. I. (2003). Latent Dirichlet allocation. Journal of Machine Learning Research, 3, 993-1022. https://doi.org/10.1162/jmlr.2003.3.4-5.993.

Brady, D. W. (2014, February 17). Sure, Congress is polarized. But other legislatures are more so. - The Washington Post. The Washington Post: The Monkey Cage. Washington, DC. Retrieved January, 30, 2019, from https://www.washingtonpost.com/news/monkey-cage/wp/2014/02/17/ sure-congress-is-polarized-but-other-legislatures-are-more-so/?utm_term=.f0fa484bdc 99

Chong, D., \& Druckman, J. N. (2007a). Framing public opinion in competitive democracies. American Journal of Political Science, 101(4), 637-655. https://doi.org/10.1017/S0003055407070554.

Chong, D., \& Druckman, J. N. (2007b). A theory of framing and opinion formation in competitive elite environments. Journal of Communication, 57(1), 99-118. https://doi.org/10.1111/j.1460-2466.2006.00331.x.

De Vreese, C. H. (2005). News framing: Theory and typology. Information Design Journal \& Document Design, 13(1), 51-62. 
Downs, A. (1957). An economic theory of democracy. New York: Harper.

Gentzkow, M., Shapiro, J. M., \& Taddy, M. (2018). Congressional record for the 43rd-114th congresses: Parsed speeches and phrase counts. Stanford, CA: Stanford Libraries. https:// data.stanford.edu/congress_text.

Gerring, J. (2009). The case study: What it is and what it does. In R. E. Goodin (Ed.), The Oxford handbook of comparative politics. Oxford: Oxford University Press. https://doi.org/10.1093/oxfordhb/9780199566020.003.0004.

Gerrish, S. M., \& Blei, D. M. (2012). How they vote: Issue-adjusted models of legislative behavior. In F. Pereira, C. J. C. Burges, L. Bottou, \& K. Q. Weinberger (Eds.), Advances in neural information processing systems 25. Red Hook, NY: Curran Associates. https://doi.org/10.1111/j.1751-1097.2010.00727.x.

Green-Pedersen, C., \& Mortensen, P. B. (2010). Who sets the agenda and who responds to it in the Danish parliament? A new model of issue competition and agenda-setting. European Journal of Political Research, 49(2), 257-281. https://doi.org/10.1111/j.1475-6765.2009.01897.x.

Grimmer, J. (2010). A Bayesian hierarchical topic model for political texts: Measuring expressed agendas in senate press releases. Political Analysis, 18(1), 1-35. https://doi.org/10.1093/pan/mpp034.

Grimmer, J., \& Stewart, B. M. (2013). Text as data: The promise and pitfalls of automatic content analysis methods for political texts. Political Analysis, 21(03), 267-297. https://doi.org/10.1093/pan/mps028.

Hänggli, R., \& Kriesi, H. (2010). Political framing strategies and their impact on media framing in a swiss direct-democratic campaign. Political Communication, 27(2), 141-157. https://doi.org/10.1080/10584600903501484.

Helbling, M. (2014). Framing immigration in Western Europe. Journal of Ethnic and Migration Studies, 40(1), 21-41. https://doi.org/10.1080/1369183X.2013.830888.

Hooghe, L., \& Marks, G. (2018). Cleavage theory meets Europe's crises: Lipset, Rokkan, and the transnational cleavage. Journal of European Public Policy, 25(1), 109-135. https://doi.org/10.1080/13501763.2017.1310279.

Johnston, R. (2015). Canada is polarizing-and it's because of the parties. In J. Sides \& D. J. Hopkins (Eds.), Political polarization in American politics (p. 120). London: Bloomsbury Academic. https://www.washingtonpost.com/news/monkey-cage/wp/2014/02/18/canadais-polarizing-and-its-because-of-the-parties/?utm_term=.72486dceb2ad.

Lahav, G. (1997). Ideological and party constraints on immigration attitudes in Europe. Journal of Common Market Studies, 35(3), 377-406. https://doi.org/10.1111/1468-5965.00067.

Lefevere, J., Sevenans, J., Walgrave, S., \& Lesschaeve, C. (2017). Issue reframing by parties: The effect of issue salience and ownership. Party Politics, 25(4), 507-519. https://doi.org/10.1177/1354068817736755.

Lefevere, J., Tresch, A., \& Walgrave, S. (2015). Introduction: Issue ownership. West European Politics, 38(4), 755-760. https://doi.org/10.1080/01402382.2015.1039375.

Lowe, W. (2008). Understanding wordscores. Political Analysis, 16(4), 356-371. https://doi.org/10.1093/pan/mpn004.

Morgenthau, H. J. (1960). Politics among nations. The struggle for power and peace. International Affairs, 25(2), 192. https://doi.org/10.2307/2086875.

Nelson, T. E., \& Kinder, D. R. (1996). Issue frames and group-centrism in American public opinion. The Journal of Politics, 58(4), 1055-1078. https://doi.org/10.2307/2960149.

Nguyen, V.-A., Boyd-Graber, J., Resnik, P., \& Miler, K. (2015). Tea Party in the House: A hierarchical ideal point topic model and its application to republican legislators in the 112th congress. In Proceedings of the 53rd Annual Meeting of the Association for Computational Linguistics and the 7th International Joint Conference on Natural Language Processing (Vol. 1: Long Papers). https://doi.org/10.3115/v1/P15-1139.

Odmalm, P. (2011a). Political parties and "the immigration issue": Issue ownership in Swedish parliamentary elections 1991-2010. West European Politics, 34(5), 1070-1091. https://doi.org/10.1080/01402382.2011.591098. 
Odmalm, P. (2011b). Political parties and 'the immigration issue': Issue ownership in Swedish parliamentary elections 1991-2010. West European Politics, 34(5), 1070-1091. https://doi.org/10.1080/01402382.2011.591098.

Odmalm, P. (2012). Party competition and positions on immigration: Strategic advantages and spatial locations. Comparative European Politics, 10(1), 1-22. https://doi.org/10.1057/cep.2010.20.

Odmalm, P. (2014). The party politics of the EU and immigration. London: Palgrave Macmillan UK. https://doi.org/10.1057/9781137462510.

Odmalm, P., \& Super, B. (2014). If the issue fits, stay put: Cleavage stability, issue compatibility and drastic changes on the immigration "issue". Comparative European Politics, 12(6), 663 679. https://doi.org/10.1057/cep.2014.24.

Petrocik, J. R. (1996). Issue ownership in presidential elections, with a 1980 case study. American Journal of Political Science, 40(3), 825-850. https://doi.org/10.2307/2111797.

R Core Team. (2018). R: A Language and Environment for Statistical Computing. R Foundation for Statistical Computing, Vienna, Austria.https://www.r-project.org/

Ramey, A., Klingler, J., \& Hollibaugh, G. (2016). Measuring elite personality using speech. Rochester, NY. https://papers.ssrn.com/abstract $=2605644$

Roberts, M. E., Stewart, B. M., \& Tingley, D. (2017). stm: R package for structural topic models. Journal of Statistical Software, 10(2), 1-42. https://doi.org/10.18637/jss.v000.i00.

Sakamoto, T., \& Takikawa, H. (2018). Cross-national measurement of polarization in political discourse: Analyzing floor debate in the U.S. the Japanese legislatures. In Proceedings 2017 IEEE International Conference on Big Data, Big Data 2017. Piscataway, NJ: IEEE. https://doi.org/10.1109/BigData.2017.8258285.

Sniderman, P. M., \& Theriault, S. M. (2004). The structure of political argument and the logic of issue framing. In W. E. Saris \& P. M. Sniderman (Eds.), Studies in public opinion (pp. 133 165). Princeton, NJ: Princeton University Press.

Stubager, R., \& Slothuus, R. (2013). What are the sources of political parties' issue ownership? Testing four explanations at the individual level. Political Behavior, 35(3), 567-588. https://doi.org/10.1007/s11109-012-9204-2.

Sulkin, T. (2005). Issue politics in congress. Issue Politics in Congress. New York: Cambridge University Press. https://doi.org/10.1017/CBO9780511616013.

Vliegenthart, R., \& Walgrave, S. (2011). Content matters: The dynamics of parliamentary questioning in Belgium and Denmark. Comparative Political Studies, 44(8), 1031-1059. https://doi.org/10.1177/0010414011405168.

Walgrave, S., \& De Swert, K. (2007). Where does issue ownership come from? From the party or from the media? Issue-party identifications in Belgium, 1991-2005. Harvard International Journal of Press/Politics, 12(1), 37-67. https://doi.org/10.1177/1081180X06297572.

Open Access This chapter is licensed under the terms of the Creative Commons Attribution 4.0 International License (http://creativecommons.org/licenses/by/4.0/), which permits use, sharing, adaptation, distribution and reproduction in any medium or format, as long as you give appropriate credit to the original author(s) and the source, provide a link to the Creative Commons licence and indicate if changes were made.

The images or other third party material in this chapter are included in the chapter's Creative Commons licence, unless indicated otherwise in a credit line to the material. If material is not included in the chapter's Creative Commons licence and your intended use is not permitted by statutory regulation or exceeds the permitted use, you will need to obtain permission directly from the copyright holder.

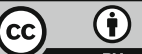

